\title{
Determinants of Overall HIV/AIDS Knowledge Among Adolescent Girls and Young Women Aged 15-24 Years in Malawi
}

Chrispin Mandiwa ( $\sim$ crismandiwa@yahoo.com )

Bernadetta Namondwe

Mtondera Munthali

\section{Research}

Keywords: HIV/AIDS, Comprehensive knowledge, Young women, Malawi

Posted Date: July 2nd, 2020

DOl: https://doi.org/10.21203/rs.3.rs-39387/v1

License: (c) (i) This work is licensed under a Creative Commons Attribution 4.0 International License.

Read Full License 


\section{Abstract}

Background HIV epidemic remains a major public health issue in Malawi especially among adolescent girls and young women. Having accurate knowledge about HIV/AIDS is a key component of preventing the spread of HIV among adolescent girls and young women. Therefore, the aim of this study was to identify the determinants of overall HIV/AIDS knowledge among adolescent girls and young women in Malawi.

Methods The study was based on cross-sectional data from the 2015-2016 Malawi Demographic and Health Survey. It involved 10132 adolescent girls and young women aged 15-24 years who reported to have ever heard of HIV/AIDS. The outcome variable was overall HIV/AIDS knowledge. Data were analysed by using descriptive statistics, cross-tabulation and multivariable logistic regression models. All the analyses were performed using complex sample analysis procedure of the Statistical Package for Social Sciences (SPSS version 22) to account for complex survey design.

Results Of the total 10132 participants included in the study, 82.2\% $(n=8326)$ had high overall knowledge of HIV/AIDS. Around $25 \%$ of the participants did not know that using condoms consistently can reduce the risk of HIV and $23 \%$ of the participants believed that mosquitoes could transmit HIV. Several factors were significantly associated with women's overall HIV/AIDS knowledge. Women who were aged 20-24 years $(A O R=1.16 ; 95 \% \mathrm{Cl}=1.04-1.29)$, women from rich households $(\mathrm{AOR}=1.22 ; 95 \% \mathrm{Cl}=1.08-$ 1.39), women who were working ( $A O R=1.29 ; 95 \% \mathrm{Cl}=1.16-1.44)$, women who were listening to radio at least once a week $(\mathrm{AOR}=1.19 ; 95 \% \mathrm{Cl}=1.05-1.35)$ and women who had secondary or higher education $(\mathrm{AOR}=3.43 ; 95 \% \mathrm{Cl}=2.67-4.42)$ were more likely to have high overall knowledge about HIV/AIDS compared to their counterparts.

Conclusions The findings of this study suggest that some adolescent girls and young women in Malawi are lacking comprehensive HIV/AIDS knowledge. Lack of knowledge about HIV transmission and prevention methods among young women might pose a challenge to efforts to stop the spread of the HIV epidemic. To reduce the incidence of HIV, it is essential to design effective interventions that can increase HIV/AIDS knowledge among adolescent girls and young women in Malawi.

\section{Background}

Even though the number of AIDS-related deaths has dropped by 55\% in Malawi since 2010, HIV epidemic still remains a major public health challenge in Malawi especially among adolescent girls and young women (AGYW) aged 15 to 24 years [1]. Young women are generally considered to be the most vulnerable group with regard to HIV/AIDS compared to their male counterparts in Malawi [2]. As of 2018, the prevalence of HIV among Malawian AGYW was $4.3 \%$ compared to $2 \%$ among young men [3]. Similarly, the incidence was also high among young women with 9,900 new infections compared to 4,200 new infections among young men [3]. Understanding the dynamics of HIV transmission among AGYW is key to designing effective prevention strategies. 
Majority of new HIV infections among AGYW are transmitted through unprotected sex [4-6]. Lack of accurate knowledge about HIV/AIDS has been documented as one of the major contributing factors to the increase in the number of new HIV infections among AGYW $[7,8]$. Thus, having sound knowledge about HIV/AIDS is a necessary component of preventing the spread of HIV. Having correct HIV/AIDS knowledge on what it is, what causes it, how it is transmitted and how it can be prevented, allows individuals to recognize their own risk and facilitates changes in high risk sexual behaviour and attitudes $[9,10]$. Therefore, the importance of comprehensive HIV/AIDS knowledge in the fight against HIV/AIDS cannot be overemphasized.

Several non-clinical HIV prevention interventions such as behaviour change communication and awareness campaigns have been implemented in Malawi to halt the spread of HIV among AGYW. However, there has been no study that has assessed the levels of overall HIV/AIDS knowledge and associated factors among AGYW in Malawi. Previous studies conducted in the worst affected countries have found that despite AGYW ever heard of HIV/AIDS, their HIV/AIDS knowledge levels were appallingly low $[11,12]$. Understanding the factors that influence HIV/AIDS knowledge among AGYW can help to design effective HIV prevention programmes for reducing HIV incidence among adolescent girls and young women. Therefore, the purpose of the present study was to identify the determinants of overall HIV/AIDS knowledge among adolescent girls and young women in Malawi using a nationally representative sample.

\section{Methods}

\section{Data source and study design}

This analysis is based on the 2015-2016 Malawi Demographic and Health Survey (MDHS), a crosssectional nationally representative population-based household survey. The 2015-16 MDHS is the fifth survey that was conducted from October 2015 to February 2016 by the National Statistical Office (NSO) of Malawi in joint collaboration with the University of Malawi and the Community Health Services Unit under the Ministry of Health. Study participants were selected using a two-stage stratified cluster sampling procedure. The first stage involved selection of the primary sampling units (clusters); the second stage involved the selection of households through systematic random sampling. All men aged 15-54 years and women aged 15-49 years who were either permanent residents or visitors to the household the night preceding the survey were eligible to be interviewed using the Men's and Women's Questionnaires, respectively. The data analysed in this study was collected using women's questionnaire which collected data on a wide range of health indicators, including socio-demographic information, reproductive history and HIV/AIDS-related knowledge. A total of 24,562 women were successfully interviewed, yielding a response rate of $98 \%$. For the purposes of this study, analysis was restricted to data for 10,132 adolescent girls and young women aged 15-24 years who reported to have ever heard of HIV/AIDS. Further information regarding the methodology used in the 2015-2016 MDHS can be found in the publicly available survey report [13]. 


\section{Measurement of variables}

\section{Outcome variable}

The outcome variable for this study was overall HIV/AIDS knowledge. In the MDHS woman's questionnaire, all women who had ever heard of HIV/AIDS were asked a set of five questions on HIV/AIDS knowledge. The level of overall knowledge about HIV/AIDS was assessed by correctly identifying two major ways of preventing the sexual transmission of HIV: "knowing that consistent use of condoms during sexual intercourse and having just one uninfected faithful partner can reduce the chances of getting HIV as well as acknowledging that a healthy looking person can have HIV infection,". Furthermore, the assessment was also based on rejecting the two most common local misconceptions about HIV transmission: "that HIV can be transmitted by mosquito bites and people get HIV by sharing food with a person who has HIV". The answer categories for the above questions were "yes", "no", and "don't know". For the purpose of study, the incorrect and "don't know" responses were re-coded as 0 , while correct responses were re-coded as 1 . Thus, the score for women's overall knowledge on HIV/AIDS ranged from 0 to 5; where a woman who answered all five questions incorrectly had a score of 0 and a woman who answered any of the five questions correctly got a score between 1 and 5 . The mean value was used as a cut-off value for dichotomisation of women's overall knowledge on HIV/ AIDS scores into high vs. low knowledge. Thus, participants who had a score of 3-5 were regarded as having high HIV/AIDS knowledge, while those who had a score of $0-2$ were considered as having low knowledge. The construction of the overall HIV/AIDS knowledge variable has been published previously [14-16].

\section{Covariates}

The covariates were selected based on literature review and their availability in the DHS data set [8,1720]. The covariates included were: age (in two categories: 15-19 and 20-24), area of residence (rural vs. urban), region of residence (northern, central, southern), marital status (categorized as never married, currently married and formerly married), education level (no education, primary education and secondary or higher education), work status/paid work (working/not working), frequency of listening to radio ( not at all, less than once a week and at least once a week) and wealth index (poor, medium and rich). The wealth index was constructed by Measure DHS through weighting each asset or dwelling characteristic and standardizing the resulting wealth score to a standard normal distribution [21]. The index was provided as a wealth score separated into quintiles (poorest, poorer, middle, richer, richest) in the DHS, but for the sake of this study it was re-categorised into 3 groups by combining the first two groups and last two groups.

\section{Data analysis}

First, descriptive statistics were done and the results were presented as frequencies and percentages, and then the association between independent variables and knowledge of HIV/AIDS was tested using Pearson Chi-square test. The variables were further examined using crude (unadjusted) odds ratios. Variables found to be associated with the outcome of interest at $p$-value of $\leq 0.25$ in unadjusted logistic 
regression were then included in the multiple logistic regression model to generate adjusted odd ratios (AOR) with their corresponding 95\% confidence. Weighting, stratification and clustering variables created by the DHS were used throughout the analysis. All the analyses were performed using Complex Sample Analysis procedure of the Statistical Package for Social Sciences (SPSS version 22) to account for complex survey design. A $p$-value of less than 0.05 was considered statistically significant.

\section{Ethics statement}

The 2015-2016 Malawi Demographic and Health Survey was approved by Malawi Health Sciences Research Committee and the Institutional Review Board of ICF Macro. A written request was submitted to the DHS MEASURE and permission was granted to use the data for this study.

\section{Results}

\section{Characteristics of respondents}

Table 1 displays the socio-demographic characteristics of the participants who were included in the analysis according to their level of HIV/AIDS knowledge. Of the 10422 AGYW interviewed, $97.2 \%(n=$ 10132) reported to have ever heard of HIV/AIDS and amongst these, $82.2 \%$ had high overall knowledge of HIV/AIDS. Half of the respondents (50.1\%) were aged 15-19 years. Majority of the participants (81.4\%) were rural dwellers and nearly two thirds of the participants (64.3\%) had primary education while only $4 \%$ had no education. Almost half of the participants (49.9\%) were working, $47.2 \%$ were married and $38.6 \%$ were from rich households. Around $45 \%$ of the participants were from southern region and $52.4 \%$ of the women did not listen to radio at all. Table 1 also shows the cross-tabulation of the outcome variable with various background characteristics and the following factors: age, education, wealth index, frequency of listening to radio and work status were significantly associated with overall HIV/AIDS knowledge $(p<$ 0.05). Marital status and region of residence were not significant hence they were removed in the subsequent analysis. 
Table 1

Association between overall HIV Knowledge and various background characteristics

HIV Knowledge

Score

Variable

Age

$20-24$

Education

No education

Primary level

Secondary level or higher

Marital status

Never married

Currently married

Formerly married

Region

Northern

Central

Southern

Residence

Rural

Urban

Wealth index

Poor

${ }^{*} P<0.05 ;{ }^{* *} P>0.05$ n

Low Score

High

Score

$\begin{array}{llllll}\% & \mathbf{n} & \% & \mathbf{n} & \% & \text { P-Value }\end{array}$

$<$

$0.001^{\star}$

$5075 \quad 50.1 \quad 981$

$19.3 \quad 4094$

80.7

$\begin{array}{lll}5057 & 49.9 \quad 825\end{array}$

$16.3 \quad 4232$

83.7

$0.001^{\star}$

$\begin{array}{llllll}410 & 4.0 & 124 & 30.2 & 286 & 69.8\end{array}$

$\begin{array}{lll}6510 & 64.3 & 1333\end{array}$

$20.5 \quad 5177$

79.5

$\begin{array}{lll}3211 & 31.7 & 348\end{array}$

$10.8 \quad 2863$

89.2

$0.930^{* *}$

\begin{tabular}{llllll}
4662 & 46.0 & 828 & 17.8 & 3834 & 82.2 \\
\hline 4777 & 47.2 & 851 & 17.8 & 3926 & 82.2 \\
692 & 6.8 & 127 & 18.4 & 565 & 81.6
\end{tabular}

$0.854^{\star *}$

$\begin{array}{lll}1138 & 11.2 & 193\end{array}$

$17.0 \quad 945$

83.0

$4465 \quad 44.1 \quad 789$

$17.7 \quad 3676$

82.3

$\begin{array}{lll}4529 & 44.7 & 824\end{array}$

$18.2 \quad 3705$

81.8

$0.002^{*}$

$\begin{array}{lll}8249 & 81.4 & 1517\end{array}$

$18.4 \quad 6732$

81.6

$\begin{array}{lll}1882 & 18.6 \quad 288\end{array}$

$15.3 \quad 1594$

84.7

$<$

$0.001^{*}$

$4195 \quad 41.4 \quad 865$

$20.6 \quad 3330$

79.4 


\begin{tabular}{|c|c|c|c|c|c|c|c|}
\hline \multirow[b]{2}{*}{ Medium } & \multirow[b]{2}{*}{2026} & \multirow[b]{2}{*}{20.0} & \multicolumn{2}{|c|}{$\begin{array}{l}\text { HIV Knowledge } \\
\text { Score }\end{array}$} & \multirow[b]{2}{*}{1657} & \multirow[b]{2}{*}{81.8} & \\
\hline & & & 369 & 18.2 & & & \\
\hline Rich & 3910 & 38.6 & 571 & 14.6 & 3339 & 85.4 & \\
\hline $\begin{array}{l}\text { Frequency of listening to } \\
\text { radio }\end{array}$ & & & & & & & $\begin{array}{l}< \\
0.001^{*}\end{array}$ \\
\hline Not at all & 5314 & 52.4 & 1065 & 20.0 & 4249 & 80.0 & \\
\hline Less than once a week & 1856 & 18.3 & 300 & 16.2 & 1556 & 83.8 & \\
\hline At least once a week & 2962 & 29.2 & 441 & 14.9 & 2521 & 85.1 & \\
\hline Work status & & & & & & & $\begin{array}{l}< \\
0.001^{*}\end{array}$ \\
\hline Working & 5053 & 49.9 & 968 & 19.2 & 4085 & 80.8 & \\
\hline Not working & 5078 & 50.1 & 837 & 16.5 & 4241 & 83.5 & \\
\hline
\end{tabular}

\section{Determinants of overall HIV/AIDS knowledge among young women in Malawi}

Table 2 shows the crude odds ratios (COR) and adjusted odds ratios (AOR) for the factors influencing overall HIV/AIDS knowledge among young women in Malawi. After adjusting for other variables in the multivariate logistic regression, five factors comprising age of the woman, education, wealth index, frequency of listening to radio and respondent's work status were found to be significantly associated with women's overall HIV/AIDS knowledge. Women who were aged 20-24 years were $16 \%(A O R=1.16$; $95 \% \mathrm{Cl}=1.04-1.29)$ more likely to have high overall knowledge about HIV/AIDS compared to women aged $15-19$ years. Similarly, women from rich households were $22 \%(A O R=1.22 ; 95 \% \mathrm{Cl}=1.08-1.39)$ more likely to have high overall knowledge about HIV/AIDS compared to women from poor households. Likewise, we observed that young women who were working were $29 \%(A O R=1.29 ; 95 \% \mathrm{Cl}=1.16-1.44)$ more likely to have high overall knowledge about HIV/AIDS than those who were not working.

Furthermore, women who were listening to radio at least once a week were $19 \%(\mathrm{AOR}=1.19 ; 95 \% \mathrm{Cl}=$ $1.05-1.35$ ) more likely to have high overall knowledge about HIV/AIDS compared to women who were not listening to radio at all. Women who had primary education ( $A O R=1.72 ; 95 \% \mathrm{Cl}=1.38-2.15)$ and secondary or higher education $(\mathrm{AOR}=3.43 ; 95 \% \mathrm{Cl}=2.67-4.42)$ were more likely to have high overall knowledge about HIV/AIDS than those with no education. 
Table 2

Factors influencing overall HIV knowledge among young women in Malawi

\begin{tabular}{|c|c|c|c|c|c|c|}
\hline Variables & UOR & $95 \% \mathrm{Cl}$ & $P$-value & AOR & $95 \% \mathrm{Cl}$ & \\
\hline \multicolumn{7}{|l|}{ Age } \\
\hline $15--19$ & 1 & & & 1 & & \\
\hline $20--24$ & 1.23 & $1.11--1.36$ & $<0.001^{*}$ & 1.16 & $1.04--1.29$ & $0.006^{*}$ \\
\hline \multicolumn{7}{|l|}{ Education } \\
\hline None & 1 & & & 1 & & \\
\hline Primary school & 1.69 & $1.36-2.10$ & $<0.001^{*}$ & 1.72 & $1.38--2.15$ & $<0.001^{*}$ \\
\hline Secondary school or above & 3.58 & $2.83-4.55$ & $<0.001^{*}$ & 3.43 & $2.67--4.42$ & $<0.001^{*}$ \\
\hline \multicolumn{7}{|l|}{ Marital status } \\
\hline Never married & 1 & & & & & \\
\hline Currently married & 1.00 & $0.90-1.11$ & $0.937^{\star *}$ & -- & -- & -- \\
\hline Formerly married & 0.96 & $0.78--1.18$ & $0.715^{\star *}$ & -- & -- & -- \\
\hline \multicolumn{7}{|l|}{ Region } \\
\hline Northern & 1 & & & & & \\
\hline Central & 0.95 & $0.80--1.13$ & $0.579^{* \star}$ & -- & -- & -- \\
\hline Southern & 0.92 & $0.77--1.09$ & $0.339^{\star *}$ & -- & -- & -- \\
\hline \multicolumn{7}{|l|}{ Wealth index } \\
\hline Poor & 1 & & & 1 & & \\
\hline Medium & 1.17 & $1.02--1.34$ & $0.026^{*}$ & 1.08 & $0.94--1.24$ & $0.295^{\star \star}$ \\
\hline Rich & 1.52 & $1.35--1.71$ & $<0.001^{*}$ & 1.22 & $1.08--1.39$ & $0.002^{*}$ \\
\hline \multicolumn{7}{|l|}{ Residence } \\
\hline Rural & 1 & & & 1 & & \\
\hline Urban & 1.25 & $1.09--1.43$ & $0.002^{*}$ & 0.97 & $0.83--1.13$ & $0.674^{\star \star}$ \\
\hline \multicolumn{7}{|l|}{ Frequency of listening to radio } \\
\hline Not at all & 1 & & & & & \\
\hline
\end{tabular}




\begin{tabular}{|lcccccc|}
\hline Variables & UOR & $95 \% \mathrm{Cl}$ & P-value & AOR & $95 \% \mathrm{Cl}$ & \\
\hline Less than once a week & 1.30 & $1.13--1.50$ & $<0.001^{*}$ & 1.14 & $0.99--1.32$ & $0.070^{* *}$ \\
\hline At least once a week & 1.44 & $1.27--1.62$ & $<0.001^{*}$ & 1.19 & $1.05--1.35$ & $0.008^{*}$ \\
\hline Work status & & & & & & \\
\hline Not working & 1 & & & & \\
Working & 1.20 & $1.09--1.33$ & $<0.001^{*}$ & 1.29 & $1.16-1.44$ & $<0.001^{*}$ \\
\hline${ }^{*} P<0.005 ;{ }^{* *} P>0.005$ & & & & & & \\
\hline
\end{tabular}

\section{The level of knowledge about HIV prevention and transmission among young women in Malawi}

Figure 1 below shows the level of knowledge about HIV prevention and transmission among young women in Malawi. Over $90 \%$ of the respondents were aware that HIV cannot be transmitted by sharing food with someone who has HIV. About $85.7 \%$ of the participants knew that having one uninfected faithful partner can reduce the chances of getting HIV,84.3\% of the participants knew that a healthy looking person can have HIV, $76.7 \%$ of the respondents knew that HIV cannot be transmitted by mosquito bites and $74.6 \%$ of respondents answered correctly that consistent condom use can reduce the risk of HIV.

\section{Discussion}

The findings indicate that vast majority (97\%) of adolescent girls and young women in Malawi have ever heard of HIV/ AIDS. Although majority of AGYW in Malawi reported to have heard about HIV/AIDS, twenty-five percent of them did not know that using condoms consistently can reduce the risk of HIV. Similarly, about twenty-three percent of AGYW in Malawi believed that mosquitoes could transmit HIV. This is a worrisome finding as it suggests that some AGYW in Malawi are still lacking basic knowledge of HIV transmission as well as prevention methods. This result is consistent with the findings of a study done in Ghana [15]. The present study has revealed that age, education, wealth index, frequency of listening to radio and work status were significantly associated with overall HIV/AIDS knowledge.

This study has demonstrated a positive association between education and overall HIV/AIDS knowledge. AGYW who had attained primary education and those who had secondary or higher education were more likely to have high overall knowledge of HIV/AIDS compared to those who had no education. This finding is consistent with the studies conducted in Kenya and Ghana $[11,15]$. There are various potential explanations for the positive correlation between education and overall HIV/AIDS knowledge. Women with higher education are likely to know how to read which makes them understand the content of written information such as newspaper articles easily. Education also helps individuals to be proactive about 
their own health and to gather information to protect themselves against HIV. To reduce the risk of HIV spreading among AGYW, it is very crucial to reach out and provide HIV/AIDS information to AGYW with no education in communities.

The present study also found that young women aged 20-24 years were more likely to have high overall knowledge about HIV/AIDS compared to adolescent girls aged 15-19 years. This confirms findings of studies elsewhere [22, 23]. The possible reason why adolescent girls have low overall knowledge about HIV/AIDS is limited access to health-related information. For example, some parents/guardians in Malawi still believe that sexual and reproductive health education encourages sexual experimentation among girls. As a result, they are not open to discuss sexual and reproductive health information with adolescent girls which may lead to low knowledge of HIV among them. Therefore, there is a need to change social norms and design effective youth friendly programs that can help to increase knowledge about HIV among adolescent girls. There is also a need to empower parents, teachers and communities to freely discuss sexuality with adolescent girls and facilitate the adoption of self-protecting health behaviour among them.

The study also revealed that AGYW from rich households, those who were working as well as those who were listening to radio at least once a week had high overall HIV/AIDS knowledge compared to their counterparts. These results are consistent with previous research conducted in Sub-Saharan African Countries, where most of the participants who had good knowledge about HIV/AIDS were working, listening to radio frequently and were from rich households $[12,23]$. A possible explanation for these findings is that AGYW from rich households and those employed can easily afford and access information from media and other socio platforms compared to their counterparts. Taken together, these findings suggest a need to target women from poor households, those not working and those who do not listen to radio with appropriate interventions (such as HIV/AIDS awareness campaigns in local languages) that can enhance their overall knowledge about HIV/AIDS.

These results should be interpreted in the context of the following study limitations. Firstly, the data is confined to the last MDHS round (2015-2016) and current levels of overall knowledge about HIV/AIDS among AGYW may have changed. Secondly, this study was based on secondary data analysis and we were unable to include other potential variables that might influence HIV/AIDS knowledge but not available in the MDHS dataset. The study used secondary data that were self-reported, which is prone to recall and social desirability bias. Despite these limitations, this is the first study to explore the determinants of overall HIV/AIDS knowledge among adolescent girls and young women aged 1524 years in Malawi using a nationally representative sample. Therefore, our findings can be generalised to all AGYW in the whole country.

\section{Conclusions}

The findings of this study suggest that some AGYW in Malawi are lacking comprehensive knowledge of HIV/AIDS. Age of the woman, education, wealth index, frequency of listening to radio and respondent's 
work status were major factors influencing overall HIV/AIDS knowledge among AGYW in the country. Lack of basic knowledge about HIV transmission as well as prevention methods among AGYW in Malawi might pose a challenge to efforts to halt the spread of the HIV epidemic. In order to reduce the incidence of HIV among AGYW, it is essential to design effective interventions that can increase HIV/AIDS knowledge among AGYW in Malawi. This can be achieved through HIV/AIDS awareness campaigns in local languages as well as empowering parents, teachers and communities to freely discuss sexuality with adolescent girls and young women among others.

\section{Abbreviations}

AGYW: Adolescent girls and young women; AIDS: Acquired Immunodeficiency Syndrome; HIV: Human Immunodeficiency Virus; MDHS: Malawi demographic health survey; MNHSRC: Malawi National Health Sciences Research Committee; SSS: Sub-Saharan Africa.

\section{Declarations}

\section{Ethics approval and consent to participate}

The 2015-2016 Malawi Demographic and Health Survey was approved by Malawi Health Sciences Research Committee and the Institutional Review Board of ICF Macro. A written request was submitted to the DHS MEASURE and permission was granted to use the data for this study.

\section{Consent for publication}

Not applicable.

\section{Availability of data and materials}

The datasets used and analysed during the current study are available from the corresponding author on reasonable request. The datasets are also available at https://dhsprogram.com/. However, permission needs to be obtained from the Demographic Health Survey Programme Team.

\section{Competing interests}

The authors declare that they have no competing interests.

\section{Funding}

This research did not receive any funding. 


\section{Authors' contributions}

$\mathrm{CM}$ conceived the study, requested data from the DHS programme, performed statistical analysis, interpretation of data and spearheaded the writing of the manuscript. BN and MM contributed to the writing of the manuscript. All authors read and approved the final manuscript.

\section{Acknowledgements}

Many thanks to the ICF Macro and Measure DHS for granting us permission to use the 2015-2016 MDHS dataset to conduct this study. We are also thankful to all women who participated in the 20152016 MDHS.

\section{References}

1. UNAIDS Malawi 2018.Availableat:https://www.unaids.org/en/regionscountries/countries/malawi. Accessed 15 June 2020.

2. Price JT, Rosenberg NE, Vansia D, Phanga T, Bhushan NL, Maseko B, Brar S, Hosseinipour MC, Tang JH, Bekker L-G: Predictors of HIV, HIV risk perception, and HIV worry among adolescent girls and young women in Lilongwe, Malawi. Journal of acquired immune deficiency syndromes (1999) 2018, 77(1):53.

3. AVERT. Malawi results [Internet] 2018. Available at https://www.avert.org/professionals/hiv-aroundworld/sub-saharan-africa/malawi. Accessed 16 June 2020.

4. Mwale M, Muula A: Effects of adolescent exposure to behaviour change interventions on their HIV risk reduction in Northern Malawi: a situation analysis. SAHARA-J: Journal of Social Aspects of HIV/AIDS 2018, 15(1).

5. Sathiyasusuman A: Associated risk factors of STIs and multiple sexual relationships among youths in Malawi. PloS one 2015, 10(8):e0134286.

6. Wang W, Alva S, Wang S: HIV-related knowledge and behaviors among people living with HIV in eight high HIV prevalence countries in Sub-saharan Africa: ICF International; 2012.

7. Lin P, Simoni JM, Zemon V: The health belief model, sexual behaviors, and HIV risk among Taiwanese immigrants. AIDS Education \& Prevention 2005, 17(5):469-483.

8. Siziya S, Muula AS, Rudatsikira E: HIV and AIDS-related knowledge among women in Iraq. BMC research notes 2008, 1(1):123.

9. Bandura A: Health promotion by social cognitive means. Health education \& behavior 2004, 31(2):143-164.

10. Peterson RJDJL, Mann J: Preventing AIDS: Theories and methods of behavioral interventions, vol. 2: Springer Science \& Business Media; 1994. 
11. Ochako R, Ulwodi D, Njagi P, Kimetu S, Onyango A: Trends and determinants of Comprehensive HIV and AIDS knowledge among urban young women in Kenya. AIDS research and therapy 2011, 8(1):11.

12. De Wet N, Akinyemi J, Odimegwu C: How Much Do They Know? An Analysis of the Accuracy of HIV Knowledge among Youth Affected by HIV in South Africa. Journal of the International Association of Providers of AIDS Care (JIAPAC) 2019, 18:2325958218822306.

13. ICF N: Malawi Demographic and Health Survey 2015-16. In. Zomba, Malawi, and Rockville, Maryland, USA; 2017.

14. Rirash F: The association between women's autonomy and women's HIV/AIDS knowledge and attitudes in Ethiopia. 2014.

15. Fenny AP, Crentsil AO, Asuman D: Determinants and distribution of comprehensive HIV/AIDS knowledge in Ghana. Glob J Health Sci 2017, 9(12):32.

16. Khan R, Bilal A: Knowledge about HIV and Discriminatory Attitudes toward People Living with HIV in Pakistan. Pakistan Journal of Public Health 2019, 9(1):37-41.

17. Iqbal S, Maqsood S, Zafar A, Zakar R, Zakar MZ, Fischer F: Determinants of overall knowledge of and attitudes towards HIV/AIDS transmission among ever-married women in Pakistan: evidence from the Demographic and Health Survey 2012-13. BMC public health 2019, 19(1):793.

18. Haque MA, Hossain MSN, Chowdhury MAB, Uddin MJ: Factors associated with knowledge and awareness of HIV/AIDS among married women in Bangladesh: evidence from a nationally representative survey. SAHARA-J: Journal of Social Aspects of HIV/AIDS 2018, 15(1):121-127.

19. Asaduzzaman M, Higuchi M, Sarker MAB, Hamajima N: Awareness and knowledge of HIV/AIDS among married women in rural Bangladesh and exposure to media: a secondary data analysis of the 2011 Bangladesh Demographic and Health Survey. Nagoya journal of medical science 2016, 78(1):109.

20. Asamoah CK, Asamoah BO, Agardh A: A generation at risk: A cross-sectional study on HIV/AIDS knowledge, exposure to mass media, and stigmatizing behaviors among young women aged 15-24 years in Ghana. Global health action 2017, 10(1):1331538.

21. Rutstein S, Johnson K: The DHS wealth index. DHS Comparative Reports No. 6. 2004. Calverton: ORC Macro 2017.

22. Sheikh MT, Uddin MN, Khan JR: A comprehensive analysis of trends and determinants of HIV/AIDS knowledge among the Bangladeshi women based on Bangladesh Demographic and Health Surveys, 2007-2014. Archives of Public Health 2017, 75(1):59.

23. Ankunda D: Determinants of comprehensive knowledge of HIV/AIDS among women of the reproductive age (15-49) in Uganda. 2017.

\section{Figures}




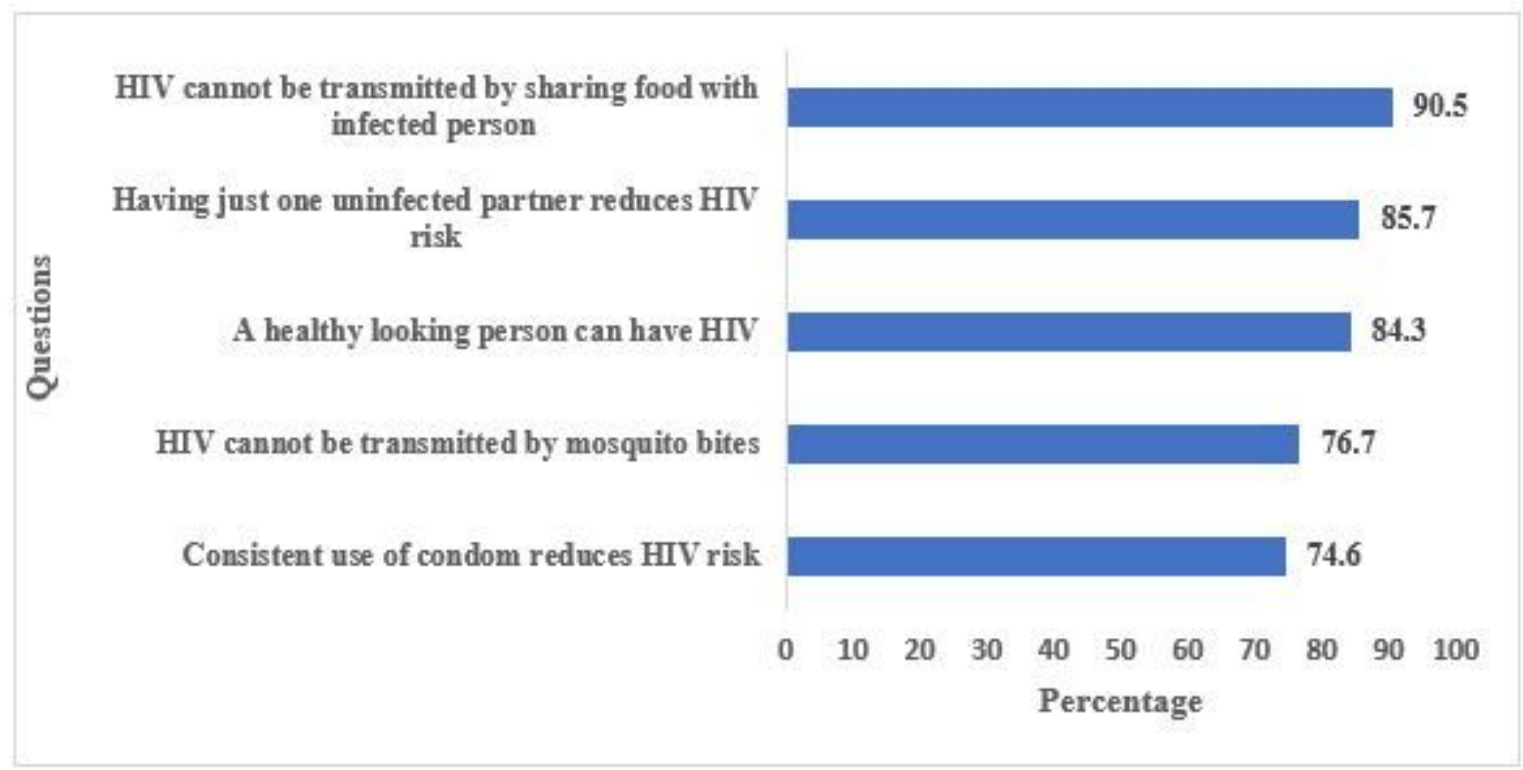

Figure 1

Percentage of young women who responded correctly to questions assessing knowledge about HIV/AIDS. 